\title{
Antipsychotic long-acting injections in clinical practice: medication management and patient choice
}

\author{
Richard Gray, Rosalyn Spilling, David Burgess and Tim Newey
}

\section{Background}

A patient-centred approach to care, focusing on recovery, demands a reconsideration of how choices are made about treatment, how this affects medication adherence, and the role of long-acting antipsychotics (LAIS) in this process.

\begin{abstract}
Aims
To explore the role of the mental health professional (particularly nurses) in helping patients manage their medication, with a specific focus of the use and administration of LAls.
\end{abstract}

\section{Method}

A pragmatic review of the literature.

\section{Results}

Patients (by experience) and mental health professionals (by training and clinical practice) are experts in the care and treatment of psychosis. When patients and clinicians make a joint decision both are more likely to adhere to the treatment plan. In this paper we consider good practice in the administration of LAls that focuses on where and when they should be given and administration techniques. Skills for talking with patients about their medication that include exchanging information, monitoring the effects of medication and making advance choices about treatment in the event of a crisis are also discussed.

\section{Conclusions}

Mental health professionals require a range of competences to help patients manage their medication effectively.

\section{Declaration of interest}

R.G. has received funding and/or fees from AstraZeneca

Pharmaceuticals, Bristol-Myers Squibb, Janssen

Pharmaceuticals, Eli Lilly, Otsuka Pharmaceuticals

and Pfizer.
Over $90 \%$ of patients with schizophrenia are prescribed medication. ${ }^{1}$ Consequently, medication management is a central and essential element of the work of mental health professionals, including nurses. Medication management includes discussing treatment choices, providing information about medication, monitoring the positive, negative and subjective effects of drugs, administering pills and giving injections. However, for many, one of the main aims of medication management is to ensure patients stick to treatment. ${ }^{2,3}$ Long-acting injections (LAIs) are also perceived as an adherence intervention for patients who are 'non-compliant' with the oral medication they have been prescribed. ${ }^{4,5}$ At first glance enhancing medication adherence is a worthy objective; patients who fail to take their medication are likely to relapse more rapidly and are more likely to be admitted involuntarily compared with those who do adhere to their treatment. ${ }^{6}$ However, many patient groups - and indeed professional groups - have argued that mental health practice needs to shift its focus away from illness management and towards recovery. ${ }^{7,8}$

The concept of 'recovery' stresses the importance of working towards goals that are defined by the patient and not by the clinician. ${ }^{9}$ To achieve this, mental health professionals need to work in a patient-centred way to enable the patients to make choices that will help them to achieve their personal goals (for example, living independently, going back to college or finding a job). Medication management is therefore about a process of shared decision-making in which two experts (clinician and patient) share information and agree jointly the best treatment plan to enable patients to achieve their personal goals. Long-acting injections (LAIs) are one of the choices that patients and clinicians should consider to enable effective management of symptoms and promote recovery. Ultimately the choice about whether to stick to this plan is the patient's. However, this does not mean that clinicians are passive; for example, if an appointment for an LAI is missed then it is important to follow up and explore with (but not blame) the patient the reasons why this was the case. Although the evidence base remains equivocal, many authors argue that unless we work with patients to make shared collaborative choices, clinical outcomes for patients will not improve. ${ }^{2,10,11}$

\section{Choice v. coercion}

What is the relevance of choice to LAIs? Choice is a fundamental value in many, particularly Western, societies and we preciously guard this right to self-determination. As health workers we must respect patients' choices even if we disagree with them. In mental health practice we do force treatment on patients because we judge they lack capacity, or present a risk, either to themselves or others or their own health. Perhaps as a consequence we more readily condone the coercion of patients into taking medication when they express a choice that we disagree with, often a reluctance to take medication. As clinicians we struggle on a daily basis with patients who do not want treatment because they do not perceive that medication helps or because they do not conceptualise their experiences within a medical illness framework. ${ }^{12}$ Long-acting injections have often been used to enforce adherence in patients who do not or will not take medication; they can be a mechanism allowing clinicians to take control. For example, Shi et al found that patients receiving LAIs had a history of more frequent relapses, were more disorganised and used illicit drugs. ${ }^{13}$ Yet it might be argued that there are potential benefits of LAIs over oral formulations in promoting recovery. So, is the job of mental health professionals (and of nurses, perhaps, in particular) to enable and respect individual patient choice, or to try to 'enforce' adherence?

When asked, many patients complain that they are not involved in treatment choices, often perceiving that choices are made for them by doctors or nurses. ${ }^{14}$ In a national patient survey 
in England in 2007 only 43\% of patients stated that they had had a say in decisions about the medication they take. In some mental health services only half of patients were told the purpose of new medication before it was started, and fewer than $40 \%$ reported that they had been told about potential side-effects. ${ }^{1}$ Ensuring that patients are involved in treatment choices has become an important quality indicator by which mental health services in England are judged. Involving patients in treatment decisions is no longer a 'nice to do', it has become a 'must do.'

Choice is not a one-off event at the start of treatment. Patients make choices each time they take a pill or accept an injection. As mental health professionals we are at risk of being in denial about the complex and sophisticated ways in which patients express choice by self-managing medication in combination with a range of other 'coping' techniques to enable them to achieve their personal goals. ${ }^{3}$ For example, patients will often intentionally miss doses to manage side-effects such as sedation or sexual dysfunction, fail to attend the out-patient clinic for an injection, ${ }^{15,16}$ or use illegal drugs such as cannabis to alleviate dysphoria. ${ }^{17}$ Although the evidence is far from compelling, many clinicians may choose LAIs to give them a sense of control over a patient's behaviour. It may be argued that LAIs are against choice because they take away the patients' ability to control their medication.

When asked, mental health professionals will almost always argue that they work in a patient-centred way; the reality is that they do not always do so, because they do not properly understand what motivates patients' choices. This was demonstrated by Kikkert et al in a study exploring patients' and professionals' view of medication adherence. ${ }^{18}$ Patients said that it was the perceived efficacy of medication that primarily influenced their choices about whether or not to adhere to treatment. Mental health professionals, conversely, said that it was the side-effects of medication that had the greatest impact on patients' medication adherence. Unless clinicians understand what drives choice in the people they work with, it is impossible for them to work in a patient-centred, collaborative way.

\section{Long-acting injections}

Mental health professionals usually perceive that a pill taken orally is the ideal way of administering medication; other methods of administration are generally reserved for patients who are more reluctant to adhere to treatment (or where the clinician wants to feel more in control). Furthermore, attitudinal studies suggest that most clinicians believe that antipsychotic LAIs are not acceptable to patients and carers. ${ }^{5}$ Many clinicians also think of the associated 'depot clinic' as an outdated model for administering treatment. Again, perhaps, our understanding of patients may be wrong. Authors have argued that patients' attitudes towards and perceptions of LAIs, and indeed of depot clinics, are generally positive. $^{4,19}$ It is ironic that mental health providers, certainly in the UK, have systematically eradicated service provision in the form of depot clinics, which were valued by their patients. Indeed, it was believed that depot clinics were out-of-date and potentially perceived as being stigmatising. ${ }^{20}$ Perhaps policy-makers, managers and clinicians need to re-evaluate LAIs (and the associated services provided) in keeping with the notion of recovery, as a positive choice that can help prevent relapse and enable patients to get on with their lives.

To help clinicians and patients make best use of LAIs we need to consider both technical competencies in administering LAIs and techniques and tools for discussing and informing choices.

\section{Where and when should LAls be administered?}

Long-acting injections should be administered at a time and in a place that is preferred by the patient. As they become more widely used, LAI clinics where patients may talk about their treatment and take part in social activities may be positively received. Their own home or a primary care setting are alternatives that patients may wish to consider. In the UK, LAIs are frequently administered by practice nurses working in primary care, emphasising the importance of effective communication between primary and secondary care services. When administering an injection, professionals have an important opportunity to discuss other aspects of the patient's well-being. This is a population at high risk of cardiovascular disease owing to a range of factors related to illness, treatment and lifestyle (for example smoking, poor diet and lack of exercise). 'Chipping away' at lifestyle factors - perhaps by regularly asking patients whether they have had any thoughts about stopping smoking - is an important technique in encouraging behaviour change and promoting well-being in patients. When patients indicate that they are ready to change, the nurse can support them to make and maintain this change.

\section{Good practice in administering injections}

Long-acting injections are administered by mental health nurses, by primary care practice nurses and, in some parts of the world, by psychiatrists and primary care doctors. Those who administer the injections need to be competent in both the technical aspects of the procedure as well as the broader medication management issues. Safe administration of LAIs is vital because once the medication is administered it is irretrievable.

When learning to administer an injection, practice makes perfect. Certainly it is vital that mental health nurses at the point of qualification must be competent in the technical administration of LAIs; although this may seem obvious, training programmes in the UK have been lauded for passing nurses as competent to practise, despite the fact that they have never given an injection. ${ }^{21}$ Experiential learning is perhaps the most effective way of teaching nurses to acquire competence in administering LAIs. Nurses who administer LAIs need:

(a) a knowledge of psychopharmacology and of the anatomy and physiology of injection-giving;

(b) skill rehearsal in administration using prosthetics;

(c) a period of supervised clinical practice with a skilled mentor.

As many patients will testify, a confident nurse can administer an injection in a way that causes little anxiety and is virtually painless. Competent nurses can also minimise the embarrassment of having an injection. Wynaden et al ${ }^{22}$ have described best practice in the administration of LAIs (see Appendix 1). It is important to pay particular attention to four key issues: possible injection sites, needle length, backtracking technique and risks associated with LAIs.

\section{Injection sites}

There are four major sites for administering LAIs (Fig. 1)

(a) Dorsogluteal site: this is also known as the upper outer quadrant and is perhaps the most popular site (except in the USA), but it is close to the sciatic nerve and is covered with abundant adipose tissue in many people. Risperidone LAI is currently licensed only for administration into the buttocks (dorsogluteal site) using the $5 \mathrm{~cm}$ needle provided in the pack. $^{23}$ 


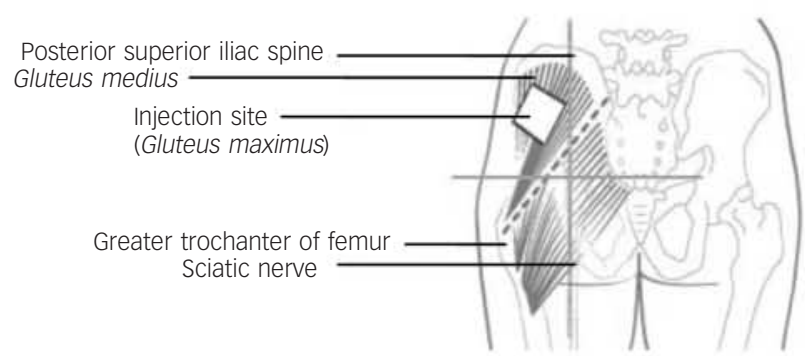

(b)

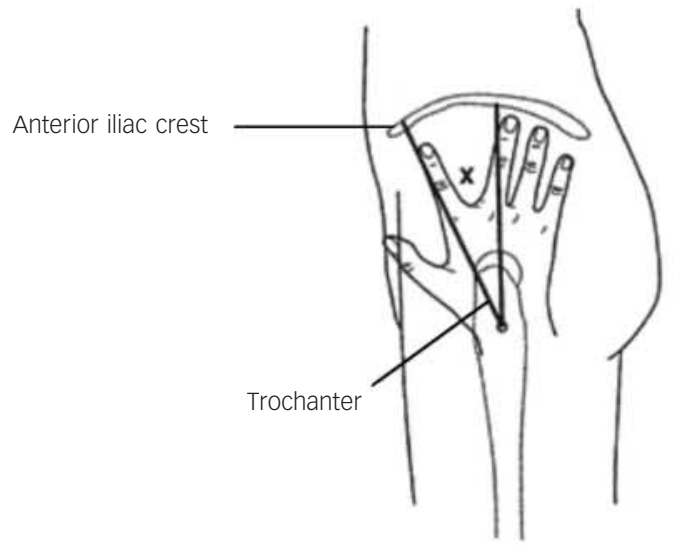

(c)

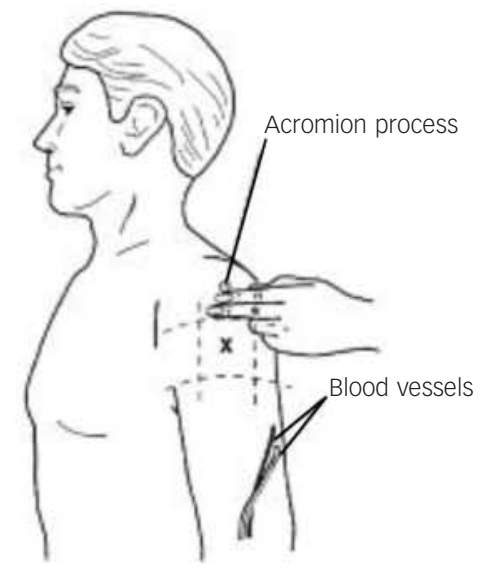

(d)

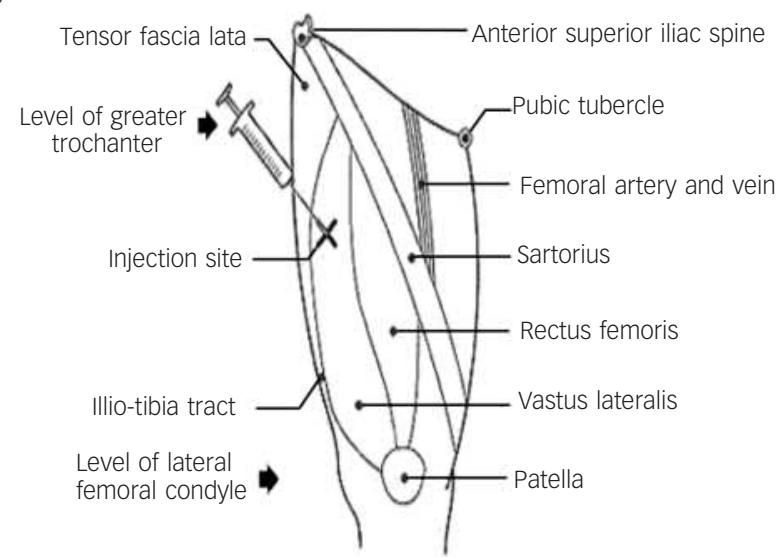

Fig. 1 Main injection sites for antipsychotic long-acting injections: (a) dorsogluteal site; (b) ventrogluteal site; (c) deltoid site; (d) vastus lateralis site. (b) Ventrogluteal site: this has few major nerves and blood vessels; the muscle is well-defined and large. Some authors have argued that this is the best site for LAI administration because of notably fewer complications, specifically injuries to the sciatic nerve. ${ }^{24}$ Additionally, it can almost be guaranteed that a standard $3 \mathrm{~cm}$ or $4 \mathrm{~cm}$ needle will penetrate muscle. ${ }^{21}$ However, in practice mental health nurses are reluctant to use this area because of problems in locating the site and a perceived risk of needlestick injury when injecting between the ' $\mathrm{V}$ ' of the index and middle fingers. ${ }^{22}$

(c) Deltoid muscle: this is rarely used, perhaps because of (rather weak) evidence suggesting that this site causes more discomfort. ${ }^{25}$ Only small volumes (less than $2 \mathrm{ml}$ ) of medication are recommended at this site because of small muscle size and risk of injury to the radial nerve and brachial artery.

(d) Vastus lateralis: this is rarely used in practice, for no clearly defined reason. The site has potential for the self-administration of LAIs, which a small number of patients have learnt to do.

\section{Needle length}

It is remarkable how infrequently nurses consider whether the needle they are using is long enough in order that the medication is injected into the muscle and not into the surrounding subcutaneous (fatty) tissue. For example, Chan et al showed using computed tomographic imaging that only a third of injections into the dorsogluteal site actually entered the muscle, dramatically limiting the efficacy of the antipsychotic and increasing the risk of fat abscesses or infection. ${ }^{26}$ Pragmatically, nurses need to use longer $(5 \mathrm{~cm})$ needles, especially in women, who have more gluteal fat, ${ }^{27}$ and in those with a body mass index greater than 30 .

\section{Backtracking, and needle speed and angle}

Despite a somewhat equivocal evidence base, the Z-track technique - using the non-dominant hand to pull the skin and subcutaneous tissue $3-4 \mathrm{~cm}$ to one side of the injection site - appears to be the best method for preventing backtracking of medication from the injection site (Fig. 2). ${ }^{28,29}$ Many nurses appear to believe that a slower rate of introducing the needle is less painful for the patient. This does not appear to be the case: pain occurs if the needle is inserted either too quickly or too slowly. ${ }^{30}$ The best way to describe the correct (least painful) way of introducing the needle is using a 'dart-like' motion. ${ }^{31}$

\section{Risks when giving LAls}

Long-acting injections have been associated with a number of complications at the site of the injection, including nodules and indurations, muscle granulomas, fibrosis, abscess formation and the accumulation of oil after repeated injections. ${ }^{32}$ Such problems have been observed in up to a quarter of patients and are associated with concentrated preparations, higher doses, larger volumes, weekly injections and prolonged treatment. ${ }^{33}$

Nurses administering LAIs also need to be mindful of the need to protect themselves against blood-borne infection by adhering to universal precautions. Rates of HIV, for example, are high among people with schizophrenia, ${ }^{34}$ yet nurses' adherence to aspects of universal precautions for infection control, specifically glove-wearing, is generally poor. ${ }^{35}$

Having explored the technical aspects of LAIs we need to consider the clinical skills and techniques that clinicians can use to have conversations with patients about starting, switching and sticking to LAIs. 'Power questions', exchanging information, monitoring the effects of treatment and enabling patients to make 


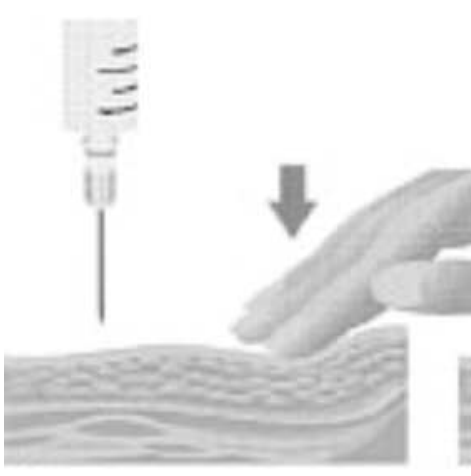

(b)

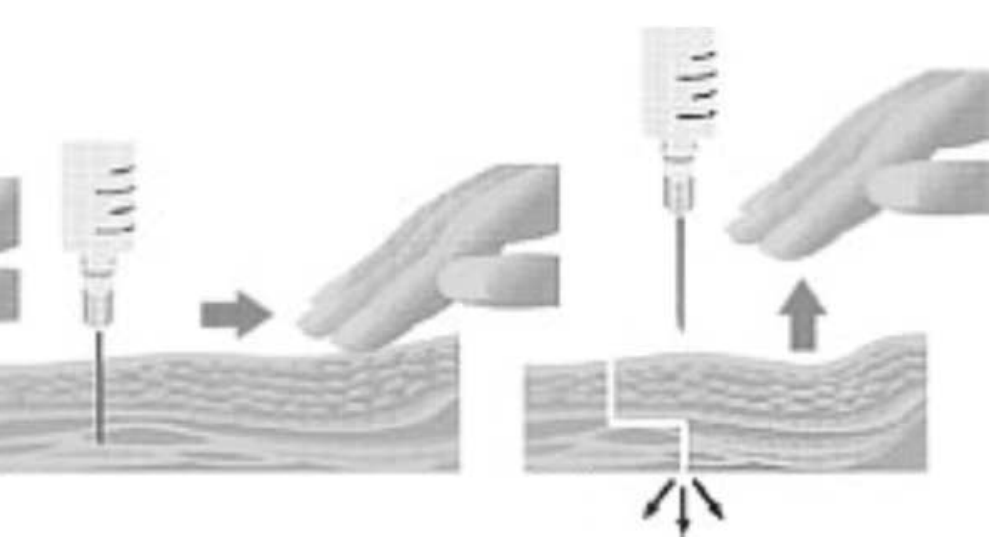

Fig. 2 The Z-tracking technique. Using your non-dominant hand to pull the subcutaneous tissue $2-3 \mathrm{~cm}$ sideways (a), pierce the skin at $90^{\circ}$ with a dart-like motion (b). Aspirate for blood; if there is none, slowly inject the medicine. Once all the medicine has been injected withdraw the needle and release the skin to break the pathway, locking in the medicine (c).

choices in advance are medication management skills that facilitate shared decision-making (see Appendix 1).

\section{Use of 'power questions'}

We have already established that patients do not perceive that they are involved in treatment decisions. ${ }^{14}$ What can patients and carers do to help them take control and enable them to consider whether an LAI is a choice that might suit them? Patients and carers can take personal responsibility in ensuring that they are involved in treatment decisions by making use of 'power questions. ${ }^{36}$ These are essential and focused questions that patients and carers can ask during a meeting with health professionals. Having a list of set questions will ensure that the patient and carer acquire the information that they need to help them make choices about treatment. Practitioners need to provide clear, factual information to patients in response to the questions they are asked. When talking about LAIs, it is important to talk about the theoretical benefits as well as the lack of compelling evidence that these are translated into better outcomes for patients. Some examples are given in Appendix 2, including the question 'What are the advantages and disadvantages of longacting injections?', promoting this formulation as a choice that patients should consider.

\section{Exchanging information}

To make treatment choices patients and their carers need information. 'Power questions' are a way of patients and carers taking control and accessing the information they need. What interventions and techniques can nurses use to provide information to patients and carers about treatment choices? Rollnick et al have proposed an elegant elicit-provide-elicit model (see Appendix 3) for exchanging information with patients, ensuring that they obtain the information they want and need. ${ }^{37}$ Exchanging information is an important element of effective medication management packages. ${ }^{2}$

\section{Monitoring the effects of LAls}

In recent years mental health professsionals have been encouraged to make use of outcome measures to establish the benefits (and side-effects) of treatment. ${ }^{38}$ Tools such as the Positive and
Negative Syndrome Scale (PANSS) that measure symptom severity are informative for clinicians, ${ }^{39}$ but often carry little meaning for patients because they do not focus on the personally relevant benefits of treatment. Part of a shared decision-making process might be working with patients to establish what their unique personally relevant target symptom is. This can be rated and tracked over time (for example, weekly on a $0-10$ scale), allowing patients to monitor for themselves the effects of taking or not taking medication, or of using injectable formulations.

Monitoring side-effects requires both objective observation and subjective reporting. Tools such as the Liverpool University Neuroleptic Side Effect Rating Scale (LUNSERS) and the Glasgow Antipsychotic Side-effect Scale are useful for the common adverse effects of antipsychotic medication. ${ }^{40,41}$ The Liverpool measure is a comprehensive 41 -item scale: patients are asked to self-report how frequently they experience side-effects from antipsychotic medication. ${ }^{42}$ This scale is widely used in clinical practice and has considerable clinical utility. ${ }^{43}$ However, these tools do not pay enough attention to the broad impact that antipsychotic medication can have on physical well-being. White et al ${ }^{44}$ describe a comprehensive Health Improvement Profile (HIP) for patients with severe mental illness (available from the author upon request). This profile enables clinicians to summarise and plan physical healthcare with patients. Systematic objective monitoring using the HIP to profile physical well-being is an important part of medication management.

\section{Making choices in advance}

In clinical practice patients and clinicians may choose not to switch to an LAI because, for example, symptoms are well controlled and a strong preference for oral medication has been expressed. So when is the most appropriate time to talk about LAIs? Many discussions about treatment choices happen when the patient is in an acutely psychotic state - quite possibly the worst time for such a conversation as relationships between patients, carers and clinicians are then often at their most strained. It is perhaps unfortunate that this is when many clinicians decide to begin LAI treatment because they believe the medication will help control chaotic behaviour and is best for the patient. There is evidence that by helping patients make choices in advance (sometimes called an advance directive or crisis plan), patient 
outcome may be enhanced. ${ }^{45}$ Discussions of choice, exploring the pros and cons of different options including LAIs and formulating an advanced plan, are best done with patients (and their carers) in advance, when they are able to reflect on their process of recovery. There is a wealth of information showing that advance choice conversations provide much useful information that will strengthen clinical care. ${ }^{46}$ It is unfortunate that this does not happen enough in practice.

\section{Conclusion}

There is an inexorable trend away from coercing patients into taking medication, even when subject to mental health law, towards a process of shared decision. In turn this can lead to a mutually acceptable treatment plan drawing on the experience and expertise of both the clinician and the patient. Long-acting injections have had something of an image problem thus far but should be considered a useful and possibly effective treatment that patients may consider choosing to help them in their recovery. Indeed, LAIs may be a positive choice to enable patients to manage their psychosis and achieve their personal goals. Mental health nurses require technical competence in administering LAIs safely and medication management skills in enabling and exploring shared choices. Power questions, exchanging information, making advance choices and monitoring the effects of treatment are all positive strategies that clinicians can use to help patients explore treatment choices. Patients (and their carers) require information in order to make choices now and in the future in the light of personal life goals, values and experience. This work is not easy and represents a real challenge for mental health practitioners, patients and their carers.

Richard Gray, RN, PhD, Faculty of Health, University of East Anglia, Norwich; Rosalyn Spilling, RN, BSC, David Burgess, RN, MSC, Mental Health Nursing, University of East Anglia, Norwich; Tim Newey, mental health service user, Bromley, Kent, UK

Correspondence: Professor Richard Gray, Faculty of Health, University of East Anglia, Norwich NR4 7TJ, UK. Email: richard.gray@uea.ac.uk

\section{Appendix 1}

\section{Recommended clinical guideline for technical administration of long-acting injections ${ }^{21,22,47}$}

1 Consider the environment in which the injection is to be given, particularly considering the dignity and privacy of the patient.

2 check the drug for prescription and time validity, medication dosage and method of administration.

3 Check patient's identity, explain procedure and ensure patient consents

4 Check medicine is licensed for recommended muscle site.

5 consider the length of needle to ensure that it is long enough to penetrate the deep muscle tissue.

6 Ensure adherence to universal precautions for infection control, e.g. always wear gloves.

7 Use a separate needle when drawing up the medication to be injected.

8 Place the patient in the prone position (where possible).

9 Select the injection site; preferably the ventrogluteal, which can be located by placing the heel of your opposing hand (i.e. left hand for right hip) on the patient's greater trochanter (the bump of bone on the outside of the hip bone). The index finger of the hand is placed on the patient's anterior superior iliac spine and the middle finger is stretched dorsally towards but below the iliac crest (the thick curved upper border of the pelvic bone). The triangle formed by the index finger, the third finger and the crest of the ilium is the injection site.
10 Consider (depending on the healthcare setting local policy) cleansing the site for $30 \mathrm{~s}$ with an alcohol wipe, allow the alcohol to dry on the skin for $30 \mathrm{~s}$.

11 Use the Z-track technique.

12 Insert the needle quickly and smoothly (a dart-like motion) at an angle of 90 degrees.

13 Aspirate for blood - if present, discard and begin the procedure again.

14 Inject medication no faster than $1 \mathrm{ml}$ per $10 \mathrm{~s}$.

15 Withdraw the needle rapidly - apply pressure to any bleeding point.

16 Do not massage.

17 Dispose of sharps safely and remove and dispose of gloves; do not recap needle.

\section{Appendix 2}

\section{Power questions ${ }^{36}$}

What choice of antipsychotic medication is available to me?

How do antipsychotic medicines work?

How effective is antipsychotic medication?

What symptoms will antipsychotic medication help with?

What are the different ways of taking antipsychotic medication (pills/ syrup/injections)?

What are the advantages and disadvantages of long-acting injections? What side-effects do different antipsychotic medicines cause? Are there different side-effects from antipsychotic long-acting injections? What is the best way to manage the side-effects I might get from antipsychotic medication?

How long will I have to take antipsychotic medication?

What will happen if/when I stop antipsychotic medication?

How do I stop taking an antipsychotic long-acting injection?

Can I switch back to pills if I don't like antipsychotic long-acting injections? Do I need any special blood tests/health checks while I am taking antipsychotic medication?

How often will my antipsychotic medication be reviewed?

\section{Appendix 3}

\section{Exchanging information}

The elicit-provide-elicit model is a three-step, time-efficient model for exchanging information with patients to ensure that patients obtain the information they want and need to make choices. ${ }^{37}$

1. Adopt a curious and enquiring questioning style to elicit from patients what they already know and then find out what they want to know about long-acting injections and their medication choices. Clarify and describe the issues to be addressed.

2. Provide the patient with clear, accurate, non-judgemental information about the treatment choices (including formulations). This information should be individually tailored rather than merely standardised using information leaflets.

3. Invite the patient to communicate his or her reflections on the information presented.

\section{References}

1 Care Quality Commission. Mental health services: the 2008 survey of community mental health services. CQC, 2009 (http://www.cqc.org.uk/ usingcareservices/healthcare/patientsurveys/mentalhealthservices.cfm)

2 Gray R, Wykes T, Edmonds M, Leese M, Gournay K. Effect of a medication management training package for nurses on clinical outcomes for patients with schizophrenia: cluster randomised controlled trial. Br J Psychiatry 2004; 185: 157-62.

3 Deegan PE, Drake RE. Shared decision making and medication management in the recovery process. Psychiatr Serv 2006; 57: 1636-9.

4 Walburn J, Gray R, Gournay K, Quraishi S, David AS. Systematic review of patient and nurse attitudes to depot antipsychotic medication. Br J Psychiatry 2001; 179: 300-7.

5 Patel MX, Nikolaou V, David AS. Psychiatrists' attitudes to maintenance medication for patients with schizophrenia. Psychol Med 2003; 33: 83-9. 
6 Nosé M, Barbui C, Gray R, Tansella M. Clinical interventions for treatment non-adherence in psychosis: meta-analysis. Br J Psychiatry 2003; 183: 197-206.

7 Faerden A, Nesvåg R, Marder SR. Definitions of the term 'recovered' in schizophrenia and other disorders. Psychopathology 2008; 41: 271-8.

8 McEvoy JP. Functional outcomes in schizophrenia. J Clin Psychiatry 2008; 69 (suppl 3): 20-4.

9 Andresen R, Oades L, Caputi P. The experience of recovery from schizophrenia: towards an empirically validated stage model. Aust $\mathrm{N} \mathrm{Z} \mathrm{J}$ Psychiatry 2003; 37: 586-94.

10 Gray R, Leese M, Bindman J, Becker T, Burti L, David A, et al. Adherence therapy for people with schizophrenia: European multicentre randomised controlled trial. Br J Psychiatry 2006; 189: 508-14.

11 Maneesakorn S, Robson D, Gournay K, Gray R. A RCT of adherence therapy for people with schizophrenia in Chiang Mai, Thailand. J Clin Nurs 2008; 15 $1-11$.

12 Mohamed S, Rosenheck R, McEvoy J, Swartz M, Stroup S, Lieberman JA. Cross-sectional and longitudinal relationships between insight and attitudes toward medication and clinical outcomes in chronic schizophrenia. Schizophr Bull 2009; 35: 336-46.

13 Shi L, Ascher-Svanum H, Zhu B, Faries D, Montgomery W, Marder SR. Characteristics and use patterns of patients taking first-generation depot antipsychotics or oral antipsychotics for schizophrenia. Psychiatr Serv 2007; 58: $482-8$.

14 Gray R, Rofail D, Newey T, Allen J. Service user satisfaction with antipsychotic medication. J Adv Nurs 2005; 52: 1-7.

15 Rummel-Kluge C, Schuster T, Peters S, Kissling W. Partial compliance with antipsychotic medication is common in patients with schizophrenia. Aust N Z J Psychiatry 2008; 42: 382-8.

16 Weiden PJ. Understanding and addressing adherence issues in schizophrenia: from theory to practice. J Clin Psychiatry 2007; 68 (suppl 14): 14-9.

17 Gregg L, Barrowclough C, Haddock G. Reasons for increased substance use in psychosis. Clin Psychol Rev 2007; 27: 494-510.

18 Kikkert MJ, Schene AH, Koeter MW, Robson D, Born A, Helm H, et al. Medication adherence in schizophrenia: exploring patients' carers' and professionals' views. Schizophr Bull 2006; 32: 786-94.

19 Waddell L, Taylor M. Attitudes of patients and mental health staff to antipsychotic long-acting injections: systematic review. Br J Psychiatry 2009; 195 (suppl 52): s43-50.

20 O'Ceallaigh S, Fahy T. Is there a role for the depot clinic in the modern management of schizophrenia? Psychiatr Bull 2001; 25: 481-4.

21 Cocoman A, Murray J. Intramuscular injections: a review of best practice for mental health nurses. J Psychiatr Ment Health Nurs 2008; 15: 424-34.

22 Wynaden D, Landsborough I, McGowan S, Baigmohamad Z, Finn M, Pennebaker $\mathrm{D}$, et al. Best practice guidelines for the administration of intramuscular injections in the mental health setting. Int $J$ Ment Health Nurs 2006; 15: 195-200.

23 Janssen-Cilag. Summary of Product Characteristics: Risperdal Consta 25 mg 37.5 mg, 50 mg. eMC, 2009 (http://emc.medicines.org.uk/emc/ document.aspx?documentID = 9939\#POSOLOGY).

24 Mclvor A, Paluzzi M, Meguid M. Intramuscular injection abscess - past lessons relearned. N Engl J Med 1991; 324: 1897-8.

25 Wink D. Discomfort after peer administered injections in a on-campus laboratory. Nurse Educat 1992; 17: 24-6.
26 Chan vo, Colville J, Persaud T, Buckley O, Hamilton S, Torreggiani WC. Intramuscular injections into the buttocks: are they truly intramuscular? Eur J Radiol 2006; 58: 480-4.

27 Haramati N, Lorans R, Lutwin M, Kaleya RN. Injection granulomas: intramuscle or intrafat? Arch Fam Med 1994; 3: 146-8.

28 Hanh K. Brush up on your injection technique. Nursing 1990; 20: 54-8.

29 Engstrom J, Giglio N, Takacs S, Ellis MC, Cherwenka DI. Procedures used to prepare and administer intramuscular injections: a study of infertility nurses. J Obstet Gynecol Neonatal Nurs 2000; 29: 159-68.

30 Katsma D, Smith G. Analysis of needle path during intramuscular injection. Nurs Res 1997; 46: 288-92.

31 Craven RF, Hirnle CJ. Fundamentals of Nursing: Human Health and Function, 2nd edn. Lippincott, 1996.

32 Jones JC, Day JC, Taylor JR, Thomas CS. Investigation of depot neuroleptic injection site reactions. Psychiatr Bull 1998; 22: 605-7

33 Hay J. Complications at site of depot neuroleptics. BMJ 1995; 311: 421.

34 Gray R, Brewin E, Noak J, Wyke-Joseph J, Sonik B. A review of the literature on HIV infection: implications for research, policy and clinical practice. J Psychiatr Ment Health Nurs 2002; 9: 405-10.

35 Hughes E, Gray R. HIV prevention for people with serious mental illness: a survey of mental health workers' attitudes, knowledge and practice. J Clin Nurs 2009; 18: 591-600.

36 Astrazeneca. Promoting Shared Decision Making in Mental Health. AstraZeneca, 2007 (http://www.choicementalhealth.com).

37 Rollnick P, Mason P, Butler C. Health Behavior Change: A Guide for Practitioners: 111-2. Churchill Livingstone, 1999.

38 Slade M, McCrone P, Kuipers E, Leese M, Cahill S, Parabiaghi A, et al. Use of standardised outcome measures in adult mental health services: randomised controlled trial. Br J Psychiatry 2006; 189: 330-6.

39 Kay SR, Fiszbein A, Opler LA. The positive and negative syndrome scale (PANSS) for schizophrenia. Schizophr Bull 1987; 13: 261-76.

40 Day JC, Wood G, Dewey M, Bentall RP. A self-rating scale for measuring neuroleptic side-effects. Validation in a group of schizophrenic patients. Br J Psychiatry 1995; 166: 650-3.

41 Waddell L, Taylor A. A new self-rating scale for detecting atypical or secondgeneration antipsychotic side-effects. J Psychopharmacol 2008; 22: 238-43.

42 Day JC, Wood G, Dewey M, Bentall RP. Liverpool University Neuroleptic Side Effect Rating Scale. Royal College of Psychiatrists, 1995 (http:// www.nhshealthquality.org/mentalhealth/toolkit/lunsers.doc).

43 Gray R, Wykes T, Parr AM, Hails E, Gournay K. The use of outcome measures to evaluate the efficacy and tolerability of antipsychotic medication: a comparison of Thorn graduate and CPN practice. J Psychiatr Ment Health Nurs 2001; 8: 191-6.

44 White J, Jones M, Gray R. Health Improvement Profile. J Psychiatr Ment Health Nurs 2009; 16: 493-80.

45 Henderson C, Flood C, Leese M, Thornicroft G, Sutherby K, Szmukler G. Effect of joint crisis plans on use of compulsory treatment in psychiatry: single blind randomised controlled trial. BMJ 2004; 329: 136.

46 Srebnik DS, Rutherford LT, Peto T, Russo J, Zick E, Jaffe C, et al. The content and clinical utility of psychiatric advance directives. Psychiatr Serv 2005; 56 : $5,592-8$.

47 Roger MA, King L. Drawing up and administering intramuscular injections: a review of the literature. J Adv Nurs 2000; 31: 574-82. 